\section{Em defesa do conceito de sociedade}

Anthony ELLIOT \& Bryan TURNER. On society. Cambridge, Polity Press, 2012. 196 páginas.

\section{Carlos Benedito Martins}

Este trabalho foi escrito por dois destacados sociólogos que têm fornecido contribuiçôes significativas na área de teoria social. Anthony Elliot é professor de sociologia na Universidade Finders, Austrália. Entre seus vários trabalhos na área de teoria social, vale destacar The Routledge companion to social theory. ${ }^{1}$ Por sua vez, Bryan Turner é professor de sociologia na City University of New York e organizou a publicação da obra The New Blackwell companion to social theory. ${ }^{2}$

Os autores de On society partem do pressuposto de que a reflexão sobre a sociedade, ou seja, o processo de sua constituição, reprodução e transformação encontra-se no cerne da sociologia. Para eles, uma clara explicitação do conceito de sociedade continua desafiando a disciplina em sua fase atual. Ressaltam que o complexo processo de globalização econômica, política e cultural que se intensificou a partir da década de 1970 constitui uma das faces salientes das sociedades contemporâneas. Ao longo do livro, eles procuram analisar o impacto que o processo de globalização gerou no interior da teoria social, uma vez que a sua existência tem desafiado interpretaçôes clássicas e contemporâneas voltadas para a compreensão das sociedades modernas.

A noção de sociedade, segundo os autores, tornou-se crescentemente problemática nos diais atuais no interior da teoria social e no contexto do debate público. Tal conceito vem sendo colocado sob suspeição por distintas tradições analíticas. Elliot e Turner consideram que Charles Lemert, em seu livro Sociology after the crisis, ${ }^{3}$ traçou de forma perspicaz os percalços que esta noção vem enfrentando no pensamento social contemporâneo. As reflexôes de Ulrich Beck, por seu turno, constituem um ataque frontal ao conceito de sociedade, na medida em que sua existência se transformou numa "categoria zumbi", ou seja, designa instituiçôes sociais que estão "mortas e ainda vivas". Para Beck, o termo sociedade converteu-se numa palavra fantasmagórica pronunciada por agentes cada vez mais individualizados que conduzem suas vidas descoladas de instituiçôes sociais, tais como família, classe social e bairro residencial, as quais numa fase inicial do processo de modernização possuíam um peso considerável na regulação social de suas vidas. ${ }^{4}$

Os autores assinalam que expressōes como "morte da sociedade", "fim do social", "fragmentação do sistema social", "implosão de formas de sociabilidade" tornaram-se frequentes nos debates acadêmicos atuais, de tal modo que a discussão sobre "sociedade" passou a ser um tema antiquado e enfadonho. Um sentimento de obsolescência a respeito do conceito espraiou-se em diferentes tendências do pensamento social contemporâneo. Pensadores e políticos conservadores consideram que a dinâmica das sociedades modernas produziu em seu interior forças sociais que desencadearam situações de aguda desordem coletiva, engendrou profundas discordâncias culturais, de tal forma que vem ocorrendo um contínuo e sensível colapso moral da vida coletiva. Nessa perspectiva, o conceito de sociedade não possui nenhuma significância intelectual para eles.

Os pós-modernistas, segundo os autores, tendem a identificar a sociedade de forma negativa, uma vez que em suas análises ela tende a inculcar nos indivíduos falsas crenças, mitologias e ideologias. Nesta apreensão analítica, a sociedade passou a ser identificada como um espaço no qual ocorrem relações de forças políticas e econômicas e múltiplas formas de dominação e exploração humana. O conceito de sociedade expressa uma das categorias universais que causam profundo desgosto intelectual aos pós-modernistas. Jean Baudrillard, por exemplo, declarou o fim da existência do social, uma vez que este regride na própria medida do desenvolvimento das instituições modernas. ${ }^{5}$ Segundo os autores, várias teóricas feministas e pós-feministas, por sua vez, afirmam que o conceito foi elaborado fundamentalmente no universo masculino e contém em si as marcas da dominação patriarcal. Para alguns pensadores de esquerda, por outro lado, a noção de sociedade encontra-se num um beco sem saída diante do avanço do neoliberalismo, expressando também uma atitude de complacência diante do Estado de bem-estar social e mostrando-se inábil em formular um projeto capaz de realizar 
profundas transformaçôes no modo de ser das sociedades contemporâneas. Para alguns teóricos da globalização, tal como John Urry, também ocorre neste âmbito uma situação de difícil sobrevivência do conceito de sociedade, já que o Estado-nação, que constituiu um dos seus pilares básicos, encontra-se em um acelerado processo de corrosão. ${ }^{6}$

Por outro lado, como mostram Elliot e Turner, determinadas análises formuladas tanto pelos pensadores clássicos como por sociólogos contemporâneos sobre o capitalismo industrial permanecem significativas teoricamente. No entanto, elas têm sido desafiadas empiricamente quando confrontadas com as profundas e velozes transformaçōes sociais da sociedade contemporânea, motivadas pela intensificação do processo de globalização econômica, política, cultural, e pelo desenvolvimento de sofisticadas tecnologias de comunicação.

Como o conceito de sociedade em sociologia tem sido construído historicamente tomando como unidade empírica o Estado-nação e seus contornos territoriais, o campo sociológico se mostra seguro ao examinar diversas instituiçōes nacionais que operam em fronteiras territoriais demarcadas. Contudo, essa postura analítica se traduz em uma atitude vacilante teoricamente diante da existência de fenômenos que transbordam as fronteiras nacionais, tais como corporaçōes transnacionais, crescente fluxo de mobilidade de pessoas e ondas de migrações, deslocamento de capital financeiro que migra velozmente de um país para outro, desenvolvimento de novas tecnologias de comunicação que conectam indivíduos situados em diferentes localidades no planeta. Ao assumir que a sociedade pré-existe às diferentes formas de relaçōes sociais, a conduta analítica atrelada aos limites do Estado-nação tem se mostrado incapaz de analisar as diferentes formas de relações sociais existentes na sociedade contemporânea. A questão que os autores procuram levantar e discutir é se esta abordagem permite compreender determinados problemas concretos da sociedade contemporânea, uma vez que num contexto de globalização as relações sociais não se confinam nos limites das sociedades nacionais, mas tendem a estender-se para além de suas fronteiras. ${ }^{7}$

On society tem como principal objetivo (re)valorizar o conceito de sociedade, distanciando-se de diversas vertentes do pensamento social contemporâneo que assumem a posição da "morte da sociedade", bem como da postura analítica que preconiza o advento de uma era "pós-social". ${ }^{8}$ Assim, Elliot e Turner mantêm intenso diálogo intelectual com pensadores clássicos e contemporâneos que forneceram contribuiçôes significativas sobre a conceituação da sociedade.Os autores deixam claro que não pretenderam realizar um trabalho sobre a história da teoria social. Movimentam-se alternadamente entre contribuições contemporâneas e clássicas sobre o conceito de sociedade, evitando construir um cenário intelectual que ressalte as oposições entre determinados autores e suas concepções. Ao contrário, enfatizam que, embora autores discutidos no livro possuam matrizes teóricas divergentes, suas análises apresentam certas convergências na apreensão da sociedade moderna.

$\mathrm{O}$ argumento central é de que a sociedade, do ponto de vista tanto teórico quanto da realidade vivida pelos agentes sociais, apresenta três conceituaçôes relevantes: sociedade como estrutura; sociedade como solidariedade e sociedade como processo criativo. Essas três concepções inicialmente formuladas no final do século XIX têm experimentado consideráveis transformaçôes ao longo do tempo. Os autores realçam as múltiplas formas pelas quais esses três sentidos se vinculam, ora se entrelaçando, ora mantendo relações conflituosas.

A concepção de sociedade como estrutura, na perspectiva dos autores, procura ressaltar os aspectos de competição, conflito, concorrência e rivalidade entre os atores sociais. Ao mesmo tempo também contempla dimensões morais e de regras de conduta que permeiam as relações sociais. A sociologia historicamente surgiu como discurso da ordem social proclamando o primado da estrutura social sobre a existência dos indivíduos e enfatizando o poder das normas sociais na orientação de suas condutas. A este propósito, os autores fazem menção ao trabalho de Robert Nisbet, The sociological tradition, sublinhando que a sociologia representou, para Nisbet, um dos diversos movimentos culturais que forneceu explicação sobre as consequências sociais das revoluçōes industrial e francesa. As correntes liberais e socialistas foram importantes na constituição inicial da sociologia, mas, para 
Nisbet, foi decisiva naquele momento a influência do pensamento conservador. Conceitos sociológicos, tais como autoridade, sagrado, comunidade, foram forjados pelos pensadores conservadores que tinham como alvo crítico as posturas individualistas na análise da vida social.

Para Elliot e Turner, apesar das diferenças analíticas entre os pensadores clássicos da sociologia, há certa convergência no sentido de ressaltar o caráter estrutural da sociedade. Durkheim assinalou que o tipo de solidariedade específica que predomina na sociedade moderna propicia uma reciprocidade moral nas interações sociais e constitui uma das bases da produção da ordem social. Karl Marx, ao salientar a instrumentalização da natureza e da humanidade aprisionada pela lógica do capitalismo, ressaltou que as relaçôes sociais se encontram submetidas a um determinado tipo histórico de divisão de trabalho que se impõe aos indivíduos, independentemente de suas vontades. Max Weber, que procurou libertar a sociologia de conceitos coletivos ao longo de sua obra, tratou de forma incessante estruturas de poder e de autoridade. A obra de Parsons enfatizou a temática da coesão social, privilegiando teoricamente os conceitos de sistema e estrutura social e salientando o papel da interiorização de normas sociais no processo de reprodução da sociedade.

$\mathrm{O}$ advento de diversas formas de globalização, o desenvolvimento de novas tecnologias de informação, a formação e a expansão de comunidades multiculturais tiveram forte impacto na concepção da sociedade como estrutura. Esse intrincado e complexo processo sócio-histórico que marca as sociedades atuais aguçou as contradições sociais e causou uma pesada carga emocional para as camadas sociais excluídas dos benefícios da globalização. Para os autores, houve uma guinada marcadamente conservadora tanto no discurso teórico quanto no plano político. Cada vez mais, a concepção de sociedade como estrutura vem sendo utilizada como uma forma de combate à diversidade cultural, como uma maneira de contestar os diversos movimentos sociais que visam questionar os fundamentos econômicos, sociais e culturais do capitalismo avançado. Essa modalidade de discurso também representa um recurso estratégico para combater as revoltas sociais que têm ocorrido com frequência em diversas cidades globais. ${ }^{9}$

A intensificação da mobilidade de pessoas e a ocorrência de ondas migratórias contribuíram também para a emergência de práticas políticas que vêm sendo adotadas em vários países, que assumem uma posição de custódia da sociedade como estrutura. Nesse sentido, a ênfase do discurso político de segurança nacional e/ou internacional passou a ser a proteção dos territórios nacionais contra a "imigração ilegal", o combate ao "terror" e a neutralização do terrorismo internacional. Para Elliot e Turner, existe uma visível contradição entre a intensidade dos diferentes fluxos que ocorrem numa escala global e a criação do que Turner denomina "sociedade enclave", ${ }^{10}$ ou seja, a criação de poderosas agências nacionais e internacionais que pretendem regular o espaço territorial dos países e imobilizar a circulação de povos, bens e serviços.

A versão conservadora dos defensores dessa concepção de sociedade tende a construir discursos de teor marcadamente moralista, que atacam de forma contundente os defensores da legislação favorável ao aborto e dos que atuam em favor da regulação da pornografia. Em contrapartida, pregam valores em defesa da família, acentuam o valor moral da fidelidade nas relações matrimoniais e procuram criminalizar a prática da homossexualidade etc. Essas posiçôes fundamentalistas expressam um confronto entre a concepção de sociedade como estrutura, que privilegia a disciplina e defende certas instituiçõos sociais, e uma postura que percebe a sociedade com maior fluidez, procurando formas mais criativas de participação.

Os autores salientam que a concepção de sociedade como solidariedade também possui longa trajetória na análise sociológica e nas humanidades. Em sua fase inicial, esta formulação procurava combater intelectualmente as concepçôes utilitaristas, individualistas e o conceito de homo economicus, dada sua incapacidade de compreender a importância dos vínculos sociais. O processo de globalização também tem desafiado esse conceito de solidariedade, uma vez que está fundamentado numa forte integração entre os membros que compartilham a vida social - senso de pertencimento a uma comunidade com mesma linguagem e cultura. Segundo 
os autores, Ferdinand Töennies definiu os contornos do conceito que posteriormente a sociologia moderna passou a denominar "comunidade" (gemeinschat), ou seja, a existência de tipos de arranjos sociais onde predominam unidade social, ausência de individualismo e prevalência de um sentimento altamente emocional, tal como acontece nas relaçôes familiares e de vizinhança. $\mathrm{O}$ surgimento da sociedade capitalista (gesselschaft), para Töennies, corroeu o tipo de relação social que existiu anteriormente, intensificou a competição e expôs os trabalhadores a uma situação de exploração e pobreza. Na perspectiva de Alasdir MacIntyre, durante a revolução industrial as classes sociais possuíam internamente um grau de integração assentado em determinados valores comuns, mas com o intensivo processo de urbanização a vida comunitária se fragmentou e a aquela solidariedade se dissipou. ${ }^{11}$

Após a hecatombe causada por duas guerras mundiais, o movimento em direção à solidariedade coletiva foi incorporado à vida política em muitos países, e não só europeus, como resultado do legado da concepção keynesiana do Estado de bem-estar social. Durante o período pós-guerra, começou a se desenvolver uma cidadania social amparada pelas políticas públicas do Estado. $\mathrm{Na}$ avaliação dos autores, isso permitiu a neutralização de conflitos gerados por interesses econômicos e políticos. Ademais, o processo de solidariedade também se baseou na unidade linguística, cultural e religiosa de diversas sociedades nacionais. Contudo, afirmam os autores, durante as últimas décadas do século XX, muitas instituiçôes sociais que fomentavam a solidariedade foram pressionadas e corroídas pela expansão das corporações multinacionais e pela implantação de políticas neoliberais na década de 1970 que incentivaram direta ou indiretamente o desenvolvimento de um ethos individualista.

Ainda existiria espaço hoje para uma concepção de sociedade como solidariedade num contexto social marcado por um capitalismo global que tem corroído as forças políticas de sindicatos em vários países e implementado políticas neoliberais causadoras de uma pesada carga social e emocional para os indivíduos que necessitam da proteção de políticas públicas? Como pensar isso, perguntam-se os autores, diante da ocorrência de outros fenômenos sociais, para além dos já elencados, que tendem a solapar os laços de solidariedade social? Fenômenos como o deslocamento em grande escala de trabalhadores rurais para megacidades, obrigando-os a abandonar suas relaçôes familiares, costumes culturais para ingressar num mundo atomizado e marcado por uma impetuosa concorrência individual. Os autores assinalam que o movimento de migração constituiu uma tendência mundial na sociedade contemporânea, no entanto ressaltam as peculiaridades que esse fenômeno assume em países asiáticos como a Malásia e a China. ${ }^{12}$

Por outro lado, os autores apontam, entre outros pensadores sociais, as reflexões de Jurgen Habermas e Jeffrey Alexander, que, partindo de pressupostos analíticos diferentes, procuram enfatizar a pertinência do conceito de solidariedade num contexto de globalização e de multiculturalismo. Nessa direção, Habermas salienta que a solidariedade foi inicialmente pensada num contexto das sociedades nacionais e que, portanto, deve modificar seus mecanismos analíticos de tal modo a se abrir para um horizonte global no qual emergem valores cosmopolitas que possibilitam (re)pensar a criação de laços de solidariedade através de organizações e movimentos sociais transnacionais. ${ }^{13}$ Jeffrey Alexander, por sua vez, concorda que empiricamente a esfera civil das sociedades contemporâneas encontra-se fragmentada por manifestaçôes particularistas visíveis nos planos étnico e cultural. No entanto, manifesta a crença na possibilidade de se construir uma genuína esfera política na qual o multiculturalismo, ao contrário de constituir uma fonte destrutiva socialmente, possa representar uma oportunidade para a elaboração de um universo cultural baseado em valores universalistas criando vínculos de solidariedade. Em sua perspectiva, torna-se necessário (re)construir o conceito de sociedade civil abrindo espaço para a confiança, a solidariedade social e a reparação de injustiças sociais. ${ }^{14}$

$\mathrm{Na}$ perspectiva de Elliot e Turner, o conceito de solidariedade continua pertinente na análise sociológica. No entanto, nas sociedades contemporâneas, este conceito tem assumido maior complexidade quando comparado a períodos anteriores. Sua elaboração e sua prática hoje requerem certo grau de reflexividade emocional e uma abertura 
cognitiva por parte dos atores sociais. A solidariedade na sociedade contemporânea tende a fortalecer a comunicação e a interação simbólica entre os indivíduos e, ao mesmo tempo, produz múltiplos discursos. As práticas solidárias gravitam em torno do estabelecimento de diálogos em variadas esferas, mas encontram-se também incrustadas em múltiplas formas de sociabilidade, fazendo circular valores democráticos e cosmopolitas cuja visibilidade tem aumentado consideravelmente por conta de sua divulgação através de novas tecnologias de informação.

Além disso, a microanálise sociológica identifica a manifestação de modalidades espontâneas de solidariedade, formando uma rede informal de proteção e dando suporte àqueles que vivem isolados nas aglomerações urbanas. Trata-se da solidariedade voluntária - lower-case solidarity -, distinta daquela proveniente de movimentos nacionalistas e fundamentalistas - upper-case solidarity -, nos quais as relações sociais são reguladas por princípios de fidelidade política, moral e/ou religiosa e seus membros encontram-se passíveis de punição caso se desviem dos compromissos assumidos dentro desta lógica.

A concepção de sociedade como criação procura afastar-se da análise que enfatiza a existência de forças sociais que atuam sobre as condutas individuais, tão presente na ideia de sociedade como estrutura. Ao mesmo tempo, busca distanciar-se da postura que tem como alvo - num contexto de multiculturalismo - a criação de valores universais e cosmopolitas capazes de reforçar os vínculos sociais numa sociedade globalizada, que marca a concepção de sociedade como solidariedade. Essa terceira formulação visa ressaltar a emergência de um conjunto de questôes perseguidas pelos atores sociais que possuem profundas implicações políticas, tais como a disposição de realizar transformações nas estruturas de poder e a reivindicação da construção da identidade pessoal e sexual. As diferentes versões desta concepção, em geral, vislumbram um fecundo terreno no imaginário social, qual seja, a busca da liberdade e a luta pela autenticidade pessoal. Elliot e Turner chamam a atenção para o fato de que uma parte expressiva da teoria social contemporânea tem focado a questão da criatividade nos planos social e político, inspirando-se nas reflexões de Simmel que, opondo-se às rígidas determinaçôes sociais, concebia a sociedade como uma trama complexa de relações entre os indivíduos, o que de certa forma cria espaço para a iniciativa, a criatividade e o erotismo nos processos interacionais.

$\mathrm{O}$ apelo à criatividade exalta um conjunto de valores, tais como a curiosidade, a inovação, o sentimento de alegria de participar da vida social, a busca de comunicação e uma atitude de tolerância nas relações sociais. Ao mesmo tempo, a criatividade apresenta uma faceta ambígua, contingente, uma vez que se encontra na encruzilhada entre a real possibilidade de inovação e os limites impostos pelas determinaçóes sociais e culturais. Ou seja, para Elliot e Turner, a criatividade situa-se num terreno de permanente tensão entre o horizonte provável da liberdade e os limites circunscritos pela presença de diferentes formas de dominação social e cultural. $\mathrm{O}$ aspecto instigante desta concepção repousa em sua dimensão contingente, em seu aspecto indeterminado, em sua ambiguidade intrínseca, pois para os autores a criatividade pode tanto provocar efeitos sociais positivos como situações sociais opressivas. Nesse sentido, eles apontam que sociedade como ato criativo pode produzir situações e/ ou instituições voltadas à prestação de ações sociais solidárias tal como a organização da Anistia Internacional, ou pode gerar práticas genocidas, como Auschwitz ou o regime desenvolvido por Pol Po no Camboja.

Dentro desse contexto, os autores formularam a ideia de sociedades elásticas (elastic societies), visando destacar que hoje as relações sociais transbordam seus espaços territoriais, ao passo que nas sociedades tradicionais os laços entre os indivíduos tinham por base a localidade, as relações familiares e outras formas de grupos primários. $\mathrm{O}$ conceito de sociedades elásticas permite analisar as interações sociais mediadas pelas diversificadas tecnologias de comunicação e seus efeitos nos planos social e político, em contraposição às teorias críticas repletas de uma visão nostálgica das relações sociais, predominantes num período anterior. Os movimentos políticos contra regimes autoritários ocorridos no norte da África e no Oriente Médio em 2011, elucidam os autores, contaram com a telefonia portátil e com as redes sociais para a organização de suas ações. 
On society é uma expressiva contribuição para se repensar a teoria social diante dos desafios colocados pelo processo de globalização e suas múltiplas consequências sociais. Longe de descartar a relevância de análises sobre o processo de constituição e desenvolvimento das sociedades modernas, os autores ressaltam como elas continuam fertilizando a imaginação sociológica. Longe de descartar a relevância de pensadores clássicos e contemporâneos da sociologia que procuraram analisar o processo de constituição e desenvolvimento das sociedades modernas, os autores consideram que suas análises continuam fertilizando a imaginação sociológica. No entanto, eles mantêm uma postura crítica em relação às analises sociológicas que têm confinado o conceito de sociedade ao Estado-nação e seus contornos territoriais. É necessária em sua perspectiva uma reavaliação das concepções que integram o acervo da sociologia em face das novas configurações sociais marcadas pela emergência de um espaço transnacional, onde ocorre um intenso fluxo de capital financeiro, uma acentuada mobilidade de pessoas, ondas migratórias, novas tecnologias de informação, constituição de valores cosmopolitas etc. Trata-se de um livro instigante que discorre - de forma competente e embasado numa bibliografia de excelente qualidade acadêmica - sobre a pluralidade de fenômenos que surgiram no contexto do complexo processo de globalização econômica, cultural e política e que continuam desafiando nossa compreensão da sociedade atual.

\section{Notas}

1 Anthony Elliot, The Routledge Companion to social theory. Londres, Routledge, 2010. Ver também seu trabalho realizado em parceria com Charles Lemert: The new individualism: the emotional cost of globalization, Londres, Routledge, 2009.

2 Bryan Turner, The New Blackwell Companion to social theory. Oxford, Blackwell, 2010. Em parceria com Habibul Khondker, Bryan Turner publicou o trabalho Globalization East and West, Londres, Sage, 2010.

3 Charles Lemert, Sociology after crises, Boulder, Paradigm, 2004. Sobre esta questão, ver o trabalho de Willian Outwaite, The future of society, Oxford, Blackwell, 2006.
4 Ulrich Beck, The reinvention of politics, Cambridge, Polity, 1997.

5 Jean Baudrillard, À I'ombre des majorités silencieuses ou la fin du social, Paris, Denöel/Gonthier, 1982.

6 John Urry, Sociology beyond societies, Londres, Routledge, 2000.

7 Ver, a este propósito, Nicholas Gane, The future of social theory, Londres, Continum, 2004.

8 Para uma discussão a respeito do advento de uma era pós-social, ver David Holmes, Virtual politics: identity and community in cyberspace, Londres, Sage, 1997.

9 Ver Saskia Sasen, The global cities: New York, London, Tokio, New Jersey, Princeton University Press, 1991.

10 Bryan Turner, "The enclave society towards a sociology of immobility". European Journal of Social Theory, 10 (2): 287-303, 2007.

11 Alasdir MacIntyre, Secularization and moral change, Oxford, Oxford University Press, 1967.

12 Ver a esse respeito o trabalho de Victor King, The sociology of southeast Asia: transformation in a developing region, Honolulu, University of Hawai Press, 2008.

13 Jürgen Habermas, The posnational constellation: political essays, Cambridge, Polity, 2001.

14 Jeffrey Alexander, The civil sphere, Oxford, Oxford University Press, 2006.
CARLOS BENEDITO MARTINS é Professor Titular do Departamento de Sociologia da Universidade de Brasília (UnB). Foi Professor-Visitante da Universidade de Oxford em 2012. E-mail: <carlosb@unb.br>. 